\title{
Meios de Comunicação e Mentes ${ }^{1}$
}

\section{Media and Minds}

\author{
Márcio Souza Gonçalves I msg@uerj.br \\ Doutor em Comunicação pela UFRJ, Pós-Doutorando pela UFMG/GRIS/GRISPRESS, Bolsista \\ Prociência UERJ/FAPERJ, Professor do PPGCom da UERJ.
}

Ericson Telles Saint Clair I ericsonsclair@hotmail.com Doutor em Comunicação pela UFRJ, Bolsista PNAP da Biblioteca Nacional.

\begin{abstract}
Resumo
O artigo discute dois modos diferentes de teorizar a relação entre meios de comunicação, subjetividade e cultura. O primeiro modo parte de tipos de mentes, e formula classificações gerais de épocas definidas pela dominação de determinados meios de comunicação. O outro opera em uma dimensão mais local e regional, não realizando grandes classificaçóes. Finalmente, são levantadas questôes acerca da relação entre ambos os estilos de teorizaçáo Palavras-Chave: Meio de comunicação; mente; cultura.
\end{abstract}

\begin{abstract}
The paper discusses two different ways of theorizing the relationship between media, subjectivity and culture. The first one departs from types of mind to formulate general classifications of epochs defined by the domination of a certain media. The other operates in a more local and regional dimension, avoiding general classifications. Finally, questions are raised about the relationship between both styles of theorizing.
\end{abstract}

Keywords: Media; mind; culture. 


\section{Tipos De Mente E Tecnologias De Comunicação}

Richard de Bury, no ano de 1344, assim se refere ao modo como nos relacionamos com os livros:

De fato, esses dons parecem residir nos livros de forma mais útil e frutificar de forma mais fecunda para o progresso. A verdade emitida pela voz não perece caso cesse o som? $E$ a verdade escondida na mente não é, de fato, uma sabedoria esotérica, um tesouro invisivel? Ao contrário, a verdade que brilha nos livros é apreendida facilmente pelos sentidos; se manifesta pela vista quando se lê; pelo ouvido, quando se ouve alguém que está lendo e, de certo modo, também pelo tato, quando essa verdade é transcrita, revisada e conservada (BURY, 2004, p. 29. Grifos nossos).

Alberto Manguel, outro grande leitor e ensaísta, segue a mesma inspiração, porém indo mais longe:

$O$ ato de ler estabelece uma relação intima, física, da qual todos os sentidos participam: os olhos colhendo as palavras na página, os ouvidos ecoando os sons que estão sendo lidos, o nariz inalando o cheiro familiar de papel, cola, tinta, papeláo ou couro, o tato acariciando a página áspera ou suave, a encadernação macia ou dura, às vezes até mesmo o paladar, quando os dedos do leitor são umedecidos na língua (que é como o assassino envenena suas vitimas em $O$ nome da rosa, de Umberto Eco) (MANGUEL, 1997, p. 277. Grifos nossos).

A emergência das tecnologias digitais que possibilitam a leitura, e sobretudo, dos leitores de livros eletrônicos e dos tablets, por sua vez, enseja uma série de comentários (de leitores dos perfis os mais variados) sobre a perda da experiência do odor do livro novo, do ato de abrir uma página nunca antes tocada, da sensibilidade do dedo ao papel etc. Essa nostalgia causada pela perda de uma certa forma de relação com o texto possivelmente desaparecerá, na medida em que as geraçóes de leitores nascidas e formadas antes da popularização das tecnologias digitais se forem. Mas nada impede que novas nostalgias tomem forma: em um futuro distante, algum leitor poderá sentir saudade dos tablets em que era necessário um movimento dos dedos para aumentar ou diminuir o tamanho de uma imagem dentro de um livro. Porém, adentra-se aqui o terreno da futurologia, terreno perigoso e sujeito às opiniốes idiossincráticas de quem faz as "previsões".

Nota-se, assim, a partir dos exemplos de De Bury e Manguel e da observação cotidiana de leitores, uma maneira de compreender a relação entre os textos e nossa sensibilidade, fundamentada em um jogo de diversos canais sensoriais. Lemos com nossos olhos, mas também com nossos dedos, com nosso nariz, e pode-se mesmo supor uma participação do ouvido e da língua: escutamos o som do papel, experimentamos seu gosto ao umedecer os dedos para virar as páginas.

Essa maneira de fazer participar todos os nossos sentidos no ato de ler coexiste com uma outra, proposta por vários e diferentes teóricos de campos de trabalho diversos, que hipervaloriza o olho em detrimento dos outros sentidos. Apresentamos dois autores para exemplificar esta afirmação: Walter Ong e Marshall McLuhan. 
Ong é bem explícito: "Finalmente, contudo, a impressão substituiu a prolongada predominância da audição no mundo do pensamento e da expressão pelo predomínio da visão, que se iniciara com a escrita, mas não podia se desenvolver apenas com o apoio da escrita (ONG, 1998, p. 139)”. McLuhan, em páginas célebres, diz: "Só o alfabeto fonético produz uma divisão tão clara da experiência, dando-nos um olho por um ouvido e liberando o homem pré-letrado do transe tribal, da ressonância da palavra mágica e da teia do parentesco", e ainda: "Como intensificação e extensão da função visual, o alfabeto fonético reduz o papel dos sentidos do som, do tato e do paladar em qualquer cultura letrada" (McLUHAN, 2005, p. 103).

De um lado, uma ênfase em uma experiência sensória mais global, de outro uma concentração no olho. Se trata-se, entre essas duas concepções, apenas de uma diferença de grau, ou de uma oposição qualitativa, no momento não nos parece importante: quantitativa ou qualitativamente falando, são dois modos alternativos de se compreender o jogo entre os sentidos do leitor e o objeto textual lido. A esses dois modos seráo dados aqui, por uma questáo de comodidade, os nomes de compreensão global e compreensão visual da leitura, respectivamente. Sua importância está no fato de que a maneira de entender a leitura pode servir de base para sistemas de classificação de pensamentos e modos de pensar, de mentes, que por seu turno vão fundamentar visóes da história das sociedades e culturas humanas... mas este é um assunto para mais adiante. Por agora, é preciso compreender como o modo de conceber o ler, hipervalorizando um sentido, pode levar a um sistema de classificaçáo de subjetividades ou modalidades cognitivas. A reflexão de Walter Ong é exemplar e será tomada como paradigmática. Este autor opóe uma mente letrada a uma oral:

Um conhecimento mais profundo da oralidade primitiva ou primária permite-
nos compreender melhor o novo mundo da escrita, o que ele verdadeiramente é e o
que os seres humanos funcionalmente letrados realmente são: seres cujos processos de
pensamento não nascem de capacidades meramente naturais, mas da estruturaçáo
dessas capacidades, direta ou indiretamente, pela tecnologia da escrita. Sem a escrita,
a mente letrada não pensaria e não poderia pensar como pensa, não apenas quando
se ocupa da escrita, mas normalmente, até mesmo quando está compondo seus
pensamentos de forma oral. Mais do que qualquer outra invenção individual, a escrita
transformou a consciência humana (ONG, 1998, p. 93)

Têm-se assim tipos de mentes que remetem para tipos de tecnologia de comunicação utilizados. A tecnologia de comunicação oral favoreceria uma mente mais integrada, na exata medida em que mobilizaria a integralidade, ou pelo menos boa parte, dos sentidos humanos; a tecnologia de comunicaçáo escrita produziria a mente ocidental racional, fragmentada, dividida, alienada, e a prensa radicalizou esse sentido de produção. Ong, nosso caso paradigmático, não está sozinho em suas afirmações:

No essencial, os estudos contidos neste livro limitam-se a investigar as condiçôes materiais que constituiram as circunstâncias de uma mudança nos meios de comunicação social e interpessoal entre seres humanos. Subjacente a essa análise, acha-se quase sempre implícita, mas de algum modo perceptivel, a possibilidade de uma tese mais abrangente e chocante, a saber que a referida mudança tornou-se o meio de introduzir um novo estado mental - a mente alfabética, se me é permitida a expressão (HAVELOCK, 1996, p. 15-6). 
Que os nossos sentidos humanos, de que os meios são extensões, também se constituem em tributos fixos sobre as nossas energias pessoais e que também configuram a consciência e experiência de cada um de nós pode ser percebido naquela situação mencionada pelo psicólogo C. G. Jung [...] (McLUHAN, 2005, p. 37).

Os tipos de mentes são correlatos de tipos de conhecimento. A um conhecimento mais intuitivo, globalizado, um mosaico, se oporia um conhecimento mecanicizado, racionalizado, sempre parcial, o conhecimento característico do que tradicionalmente se chama de ciência:

O fato de informação visual sobre flores e plantas não poder ser armazenado [sic] verbalmente acentua o fato de que a Ciência, no mundo ocidental, sempre esteve na dependência do fator visual. Isto não deve causar surpresa numa cultura letrada baseada na tecnologia do alfabeto e que reduz até a palavra falada a um modo visual (McLUHAN, 2005, p. 182).

Observa-se assim praticamente a construção de um sistema classificatório, de uma tabela de classificação, que poderia assim ser esboçada de um modo genérico, desconsiderando diferenças pontuais entre autores:

\begin{tabular}{|l|l|l|l|l|}
\hline $\begin{array}{l}\text { Tecnologia de } \\
\text { Comunicação }\end{array}$ & $\begin{array}{l}\text { Sentidos } \\
\text { Envolvidos }\end{array}$ & Tipo de Mente & $\begin{array}{l}\text { Tipo de } \\
\text { Conhecimento }\end{array}$ & $\begin{array}{l}\text { Tipo de } \\
\text { Sociedade }\end{array}$ \\
\hline Oral & Todos & Mente Holística, Oral & Intuitivo & Tribal primitiva \\
\hline $\begin{array}{l}\text { Escrito / } \\
\text { Impresso }\end{array}$ & Visão & $\begin{array}{l}\text { Mente Letrada, } \\
\text { Consciência alfabética, } \\
\text { racional }\end{array}$ & $\begin{array}{l}\text { Racional, } \\
\text { Filosófico, } \\
\text { Científico }\end{array}$ & $\begin{array}{l}\text { Galáxia de } \\
\text { Gutenberg }\end{array}$ \\
\hline $\begin{array}{l}\text { Eletrônicos / } \\
\text { Digitais }\end{array}$ & Todos & Mente Holística & Mosaico & Aldeia Global \\
\hline
\end{tabular}

\section{Um Modo Classificatório De Teorizar}

Esse modo de teorização, eminentemente classificatório, merece alguns comentários. Em primeiro lugar, deve ser destacado que não se tem um sistema de classificação binário, opondo simetricamente dois termos, mas antes um jogo entre três termos, sendo o terceiro de algum modo uma reatualizaçáo do primeiro. Os polos extremos se organizam em torno de um eixo central. Pensar a história comunicativa e mental humana a partir de um esquema deste implica em compreender a contemporaneidade como retomando, de modo renovado, o mais antigo. Podemos ler, deste modo, em McLuhan:

Graças à eletricidade, em toda a parte retomamos os contatos pessoa a pessoa como se atuássemos na escala da menor das aldeias. É uma relação em profundidade, e sem delegação de funçôes ou poderes. Em toda parte, o orgânico suplanta o mecânico (Ibid., p. 287).

A aceleração de hoje não é uma lenta explosão centrifuga do centro para as margens, mas uma implosão imediata e uma interfusão do espaço e das funçôes. Nossa civilização especializada e fragmentada. baseada na estrutura centro-margem, subitamente está experimentando uma reunificação instantânea de todas as suas partes mecanizadas num todo orgânico. Este é o mundo novo da aldeia global (Ibid., p. 112). 
A dialética olho/ouvido, tantas vezes proposta por tantos autores (para citar alguns, e não dos mais recentes, podem ser mencionados Innis, Havelock, McLuhan, Ong), poderia levar a entender essa forma de pensar como sendo no fundo binária, mas, como dito, esse binarismo, considerado no tempo, implica uma lógica ternária, da perda do ouvido pelo olho e posteriormente de retorno do auditivo. A mesma lógica se encontra implícita nas reflexôes que pensam o tempo atual a partir da noção de pós-modernidade: o pré-moderno é sucedido por uma modernidade que conduz por seu turno a uma pós-modernidade que atualiza o pré-moderno.

Ora, tem-se aí um modo estranhamente dialético de pensamento.

Em segundo lugar, desenha-se a interessante questão de saber se esse tipo de pensamento classificatório redunda em uma forma de filosofia da história, em uma visão da história teleológica e totalizadora. Uma análise dos autores acima mencionados parece responder positivamente a essa questáo.

McLuhan pode ser apresentado como o exemplo mais evidente: a oralidade perdida e interrompida pela presença dos escritos - presença garantida sobretudo pela prensa tipográfica, pela prensa que hipertrofia o olho, introduzindo uma lógica de separação sensória, mas também psicológica em sentido mais amplo e mesmo social - essa oralidade praticamente mítica "retorna" ao termo de um longo processo de esquecimento, numa aldeia que, se é global, nem por isso é menos aldeia, portanto tribal, com toda a carga de ancestralidade que o termo porta. $\mathrm{O}$ mais recente recupera o mais antigo, fechando o ciclo. Tem-se uma visão da história compartimentalizada, com três grandes compartimentos (Tribo, Galáxia de Gutenberg e Aldeia Global) se sucedendo no tempo. Uma visão global e totalizadora, que dá conta do devir inserindo-o em um esquema de sucessão de fases ou épocas, operando o que já nomeamos anteriormente como epocalismo: uma compreensão da história como a sucessão diacrônica de épocas qualitativamente distintas umas das outras e internamente homogêneas.

De um ponto de vista teórico mais profundo, uma ligação se desenha entre o sistema de classificaçáo dos tipos de mentes engendradas pelos meios de comunicação e essa compreensão da história das sociedades humanas. O processo se inicia com a definição de tipos de mentes ligados a determinados sentidos, potencializados por meios específicos, passa posteriormente à compreensão de épocas caracterizadas por essas mentes e finaliza lendo toda a história a partir da tabela de classificação assim constituída. A classificação de base leva a classificações sucessivas que culminam em uma classificação de toda a história. Da classificação ao epocalismo, um passo nada surpreendente é dado.

Algo que foi mencionado brevemente acima deve ser destacado: no limite, essa forma de pensar, que parte dos meios como produtores de tipos de mentes, tende a totalizar a integridade da história e das culturas humanas em um esquema de compreensão geral e global. Produz-se então uma grande síntese de tudo, síntese que funciona ao mesmo tempo como teoria geral dos meios e das culturas e como teoria do modo de relação entre humanos e mídia. 
Tal síntese é claramente efetuada em McLuhan e, portanto, não exige maiores comentários. Já Harold Innis é interessante, ao contrário, precisamente pelo fracasso de seu projeto.

[...] Harold Innis estava tentando produzir em seus trabalhos de comunicação uma grande nova sintese que combinaria uma teoria da politica ou imperialismo [...] com uma teoria da consciência [... ] e uma teoria da tecnologia (baseada na sua interpretação do viés dos meios). [...] Tivesse ele tido mais dez anos de vida, teria completado com sucesso a sintese? (WATSON, 2006, p. 416. Tradução nossa.)

Esse fracasso de Innis ilustra a dimensão de uma ambição de totalização da história que certamente não é apenas sua.

Em terceiro lugar, é importante que seja ressaltado que toda classificação é potencialmente judicativa, é uma base para atribuição de valor e realização de julgamentos, o que termina por acontecer com os pensamentos baseados em uma classificação que parte das mentalidades engendradas pelos meios de comunicação.

Qualquer um dos autores mencionados poderia servir de exemplo paradigmático; Innis, contudo, apresenta o especial interesse de localizar na atualidade um período de decadência e queda.

Para este autor, a contemporaneidade é marcada por uma profunda crise, ligada aos meios de comunicação e, mais profundamente, a uma "industrialização" geral das culturas. Essa decadência teria como remédio possível um retorno à vitalidade da oralidade (que este autor, contrariamente a outros, não via nos meios eletrônicos).

As condiçóes de liberdade de pensamento estão em risco de serem destruidas pela ciência, tecnologia e a mecanização do conhecimento, e com elas, a civilização Ocidental. Meu viés está com a tradição oral, particularmente como refletida na civilização Grega, e com a necessidade de recapturar algo de seu espirito (INNIS, 2008, p. 190. Tradução nossa.).

McLuhan, valorizando positivamente a contemporaneidade, é o simétrico exato do pessimismo innisiano. Assim, por exemplo, em termos políticos:

Com a TV, chegou ao fim a votação em legendas partidárias, uma forma de especialismo e fragmentação que já não funciona. Em lugar da votação no partido, temos a imagem icônica e inclusiva. Em lugar do programa ou do ponto de vista político, temos a atitude e a posição política inclusivas. Em lugar do produto,o processo (McLUHAN, 2005, p. 361).

O que se passa com os cubanos em relação à $T V$ é a experiência da participação direta nas tomadas de posiçóes políticas (Ibid., p. 348-349).

Mas essa simetria náo deve mascarar o pertencimento comum dos dois autores a essa vontade de julgar, positiva ou negativamente, não importa, a época e seus homens. 
Todos estes três pontos acima destacados (sistema de pensamento ternário estruturado como uma filosofia da história, de caráter totalizador e judicativo) remetem ao problema do epocalismo, um modo de teorizar que pensa a história como sucessão de épocas qualitativamente distintas e delimitáveis, e obriga a pensar a difícil questão das escalas de análise utilizadas para falar de nossos processos de comunicação. É possível olhar de longe, como que através de um telescópio, para apreender em uma visada um largo espectro de acontecimentos; é possível também olhar de perto, como com um microscópio, para ver em detalhe a especificidade de algum processo. No primeiro caso, em geral cai-se no epocalismo; no segundo, nos estudos de caso singulares. Esses pontos nos obrigam igualmente a pensar a natureza das mudanças históricas que marcam as culturas humanas.

Um tal pensamento totalizador epocalista pode, portanto, ser contraposto a outro, em uma forma de pensar mais afeita à parcialidade, cuja ambição é bastante diferente da do primeiro.

\section{Um Paradigma Alternativo}

Nosso desafio seria, desta maneira, rascunhar preliminarmente uma proposta alternativa ao que denominamos epocalismo para a análise das relaçôes entre meios de comunicação e subjetividade. Trata-se de um problema teórico-metodológico bastante complexo, e este breve texto não ambiciona outra coisa senão fornecer linhas básicas a partir das quais se possa fomentar a discussão.

É possível uma investigação histórica dos efeitos subjetivos dos meios de comunicação em que não se remeta a singularidade e o movimento próprios à vida social ao domínio do idêntico? Estaria fadado ao fracasso um estudo que torne inteligíveis as relações humanas mediadas pelas tecnologias de comunicação sem submetê-las a um modelo binário/ternário, dependente do estabelecimento prévio de uma ruptura que, como passe de mágica, determine coercitivamente em cascata os modos de apreensão dos meios pelos indivíduos?

Diante desse quadro, talvez seja frutífero para os estudos em Comunicação uma aproximação às perspectivas presentes em setores da História, da Sociologia e da Filosofia que, apesar de terem bases teórico-metodológicas diferentes, têm trazido o problema da abordagem das singularidades da vida em sociedade para o primeiro plano de seus questionamentos.

Em Sociologia e Filosofia, destaca-se a releitura, nas últimas duas décadas, das obras do francês Gabriel Tarde, comumente descrito como precursor do pensamento sociológico, mas que em cujo empreendimento teórico fora acusado de excessivo psicologismo e impressionismos de toda ordem. O ponto nodal da 
reabilitação contemporânea de Tarde talvez resida precisamente na urgência que perpassa as Humanidades em geral, e a Comunicação em particular, de se pensar as relaçôes humanas de modo que não se esquive ansiosamente a evidência do baile desgovernado de diferenças, de impermanências ou de permanências transitórias, frágeis, que governam nossas vidas em sociedade. No caso em que nos detemos neste trabalho, coloca-se a urgência de se pensar uma relação entre meios de comunicação, cultura e subjetividade para além do modelo de mentes que redunda em uma filosofia da história de totalização improdutiva.

Para Tarde, tratava-se de uma desvantagem o abandono do conteúdo vivo e transformador das sociedades humanas em nome de um suposto aperfeiçoamento do método científico. Este autor notou que, em nome de uma ciência sociológica, partia-se justamente daquilo que seria preciso explicar, ou seja, a semelhança entre os mais variados tipos humanos. Se parte-se da identidade, a diferença deve ser explicada. Se o fixo, a estrutura, é a base, o movimento é obliterado ou, no máximo, é secundário, na medida em que é tido como "internalização" de regras superiores.

É preciso salientar que o privilégio da diferença não afasta a compreensão de estruturas macro. Elas serão entendidas como composiçóes inerentemente provisórias, que só garantem sua rigidez porque são atualizadas continuamente pelo movimento do socius em suas crenças e desejos conjugados. Esta atualização não é desprovida, contudo, de pequenas e aparentemente invisíveis alteraçôes sociais, que só serão por sua vez notadas quando se repetirem em diversos seres que compóem o tecido social. Em resumo, não se ignora o macro, mas se altera o viés de explicação quando o macro é decorrência do micro, e náo o oposto. $\mathrm{Na}$ base da ontologia tardeana, reflete-se a constataçáo de que nada há de fixo e permanente neste mundo, seja considerado o mundo físico-químico, o mundo vital ou o mundo social. Sendo assim, mesmo diante de uma regularidade aparentemente sólida, pululam pequenas diferenças que preparam o terreno para mudanças mais significativas do ponto de vista da percepção coletiva. Não se podem afirmar grandes regularidades sem se atentar a este ponto relevante. Assim,

se tudo vem da identidade e se tudo visa à identidade e para ela vai, qual a fonte desse
rio de variedade que nos deslumbra? Estejamos certos, o fundo das coisas não é tão
pobre, tão monótono, tão descolorido quanto supomos. Os tipos são apenas freios, as leis
são apenas diques, opostos em vão ao transbordamento de diferenças revolucionárias,
internas, nas quais se elaboram secretamente as leis e os tipos de amanhã, e que,
apesar da superposição de seus jugos múltiplos, apesar da disciplina química e vital,
apesar da razão e da mecânica celeste, acabam um dia, como os homens de uma
nação, derrubando todas as barreiras e fazendo dos próprios cacos um instrumento de
diversidade superior (TARDE, 2003, p. 78).

Se, no âmbito do pensamento sociológico e filosófico, o problema da singularidade da experiência social vem sendo recuperado nas últimas décadas, o mesmo pode ser dito no campo da historiografia, onde talvez ele se desvele 
mais concretamente na prática de uma série de historiadores contemporâneos, mais especificamente daqueles que trabalham com o domínio da chamada micro-história. Apesar de podermos indicar como ponto de confluência desta perspectiva os trabalhos de alguns historiadores italianos (dentre os quais está o célebre "O queijo e os vermes", de Ginzburg), não seria possível definir referências teóricas comuns a tais estudos, caracterizados em geral por certo ecletismo (LEVI, 1992, p. 133). A carência de uma concepção de interpretaçáo e de uma problemática micro-histórica em termos homólogos (REVEL, 1998, p. 15), contudo, não impede que tenham sido desenhados alguns princípios gerais de interrogação para o pesquisador que se aventure por esta original maneira de se produzir história.

Como indicou o italiano Giovanni Levi, o que precede o trabalho dos pesquisadores nestes casos é a convicção de que é possível mapear nas malhas da história diversos campos de indeterminação (LEVI, 1992, p. 158) da subjetividade humana em construção nas relaçôes sociais, sem necessariamente rejeitar as elaboraçôes formalizadas que permitem uma descriçáo dos quadros macro. Não estaria em jogo o embate entre particular e geral, mas a produção de um paradigma que não subordine o particular ao geral, e sim os conjugue em um profícuo tensionamento.

Para que tenhamos a dimensão concreta desta relação produtiva proposta pela micro-história, mencionamos um curioso exemplo de Levi. Haveria uma ampla discussão entre historiadores acerca da comercialização de terras em países da Europa Ocidental e da América Colonial. Dado o volume acentuado de transaçóes monetárias de terras registrado em documentos notariais, já nesta época haveria indícios de uma presença precoce de práticas capitalistas e individualistas, manifestadas na existência de uma espécie de mercado autorregulado por transações impessoais. Contudo, afirma Levi,

\begin{abstract}
apenas reduzindo-se a escala de observação a uma área extremamente localizada, foi possivel observar que o preço da terra variava segundo o relacionamento de parentesco entre as partes contratuais. Também foi possivel mostrar que eram imputados preços variáveis a terras de igual dimensão e qualidade. Desse modo, tornou-se possivel estabelecer que se estava observando um mercado complexo, em que os relacionamentos sociais e pessoais desempenhavam um papel determinante no estabelecimento do nivel de preço, do prazo de pagamento e das formas pelas quais a terra trocava de máos. Esse exemplo parece-me particularmente revelador da maneira como a micro-história procede de modo geral. Os fenômenos previamente considerados como bastante descritos e compreendidos assumem significados completamente novos, quando se altera a escala de observação. É então possivel utilizar esses resultados para extrair uma generalizaçâo mais ampla (p. 141).
\end{abstract}

Certamente, não é necessário que se adira automaticamente aos pressupostos tardeanos da diferença ou aos preceitos em construção da micro-história. Apenas levantamos a necessidade de repensar as bases epistemológicas de trabalhos da área de Comunicação, frequentemente naturalizadas, como no caso dos autores mencionados inicialmente. 
Diante do que descrevemos como epocalismo, uma estrutura de pensamento de grande força quando se abordam as relaçóes entre Tecnologias da Comunicação e percepção/subjetividade, o privilégio da perspectiva microssocial da diferença, tal como se dá no trabalho de Tarde, poderia constituir uma alternativa ao esquema de comparação entre épocas descritas homogeneamente. Se o epocalismo apresenta uma ruptura significativa entre eras idênticas em si mesmas, manifestada pelo modelo de alteraçóes de mentes, a perspectiva da diferença por sua vez multiplica, pluraliza as rupturas ao estilhaçar o domínio da vida, restituindo a ela o movimento que lhe é peculiar. O problema passa a ser, fundamentalmente, encontrar as regularidades sociais, visto que se parte da singularidade dos usos. Seria preciso uma vastíssima gama de comprovaçóes empíricas, exaustivamente catalogadas, para que se afirmasse que um determinado período histórico privilegiaria dado tipo de mente. Náo se poderia partir de antemáo de uma afirmaçáo totalizadora como esta.

Já a linhagem da micro-história nos interessa não no sentido de decalcarmos suas experiências sem refletirmos sobre as especificidades de nosso domínio de saber, mas no sentido de que nos auxilia a repensar as bases do que se entende por social, por história, por macro, micro - questóes que consideramos cruciais para a Comunicação atualmente. Como sugere o historiador Jacques Revel, "variar a objetiva não significa apenas aumentar (ou diminuir) o tamanho do objeto no visor, significa modificar sua forma e sua trama" (REVEL, 1998, p. 20). Para isso, é preciso "não mais abstrair, mas, num primeiro momento, enriquecer o real, se assim se desejar, levando em consideração os aspectos mais diversificados da experiência social" (Ibid., p. 22). Por fim, seria uma alternativa ao esquema classificatório do epocalismo, ao propor que

o recurso a sistemas classificatórios baseados em critérios explícitos (gerais ou
locais) é substituido na microanálise pela decisão de levar em consideração os
comportamentos por meio dos quais as identidades coletivas se constituem e se
deformam. Isso não implica que se ignoram nem que se desprezam as propriedades
"objetivas" da população estudada, e sim que se as trate como recursos diferenciais
cuja importância e cuja significaçáo devem ser avaliadas nos usos sociais de que são
objeto - ou seja, em sua atualização (Ibid., p. 26).

Dada a complexidade e a importância da influência social e subjetiva das diversas Tecnologias de Comunicação, é preciso que repensemos de fato as ferramentas teóricas com as quais viemos abordando nossos objetos de pesquisa. Os caminhos aqui indicados pretendem apenas estimular o debate para uma possível posterior definição mais objetiva que possa ser posta em ação.

\section{À Guisa De Não Conclusão: Questões Que Não Podemos (Mas Tentamos) Responder}

Foi abordado acima um modo de pensar a relação entre Comunicação, cultura e subjetividade que parte da noção de tipos de mentes produzidos por diferentes meios de comunicação. Esse modo de operar leva a uma compreensão da história de caráter classificatório, epocalista, judicativo, esquematista, generalista, totalizador. 
A esse modo de operar foi contraposto um segundo, que é afeito ao pequeno, não totalizador, parcial, descritivo. A uma sucessão de tipos de mentes e de épocas, se substitui uma visão da história como sendo marcada por continuidades de fundo que relativizam as mudanças de superfície, que obrigam a pensar as rupturas sobre fundos de continuidade, percebendo como diversas linhas de mudança e de permanência agem simultaneamente num dado contexto social.

Não se tendo aqui a pretensão da conclusão, serão apenas levantados alguns pontos para ulterior discussão. Mais do que responder, o que se tenta é colocar algumas questôes.

Primeiro grupo de questóes, relativo ao problema das classificaçóes: Seria possível uma forma de classificação não totalizante? Um pensamento que parte de classificaçóes básicas redundaria sempre em epocalismo e numa forma de totalização do campo classificado?

Em princípio, a primeira pergunta deve receber uma resposta negativa, pois toda classificação em seu desenvolvimento tende a organizar um campo onde cada categoria existe em oposição e diferença em relação a todas as outras (conceito de valor da linguística saussuriana). As categorias classificatórias tendem a preencher e esgotar a totalidade do possível, o que tem como correlato a totalização.

Se isso leva a um epocalismo é uma questão mais sutil e difícil de responder. Uma resposta indutiva, considerando o conjunto de autores tratados acima - portanto, bastante provisória e que precisaria ser verificada em relação a um conjunto mais estendido e diversificado de autores - seria a de que, se as categorias se ordenam diacronicamente, fatalmente tem-se alguma forma de epocalismo; se as categorias se ordenam sincronicamente, mapeando um contexto em um momento histórico dado, o epocalismo por definição, sendo um processo diacrônico, não pode ter lugar. Essa primeira resposta, porém, em termos práticos, quando aplicada ao campo da história dos meios, portanto, aplicada na diacronia, significa uma certa inelutabilidade do epocalismo...

Segundo grupo de questôes, relativas à compreensão da história: Seria possível pensar a história sem classificaçóes? Como pensar a mudança histórica sem classificar?

Uma resposta provisória: a possibilidade de uma compreensão da história fora de um regime de classificações de épocas supóe o abandono da ambição de totalização, portanto implica uma visão histórica não totalizante e parcial. Essa visão não-total do processo histórico levaria a compreender as mudanças históricas não como ruptura e corte entre momentos qualitativamente diferentes, mas como rearranjos e reorganizaçóes de elementos diversos presentes em um contexto qualquer, com a inclusão de alguns elementos novos, com a exclusão de alguns elementos antigos. Assim, por exemplo, a escrita náo levaria a uma nova mentalidade letrada, mas acrescentaria ao oral, em um arranjo diferente, um novo elemento, o que implica que grandes continuidades possam existir. Cada momento histórico seria encarado como um arranjo de elementos heterogêneos, contraditórios, complexos, e a mudança consistindo em rearranjos com possíveis introduçóes de peças novas e desaparecimentos de antigas. 
Terceiro grupo de questôes, ligadas à relação entre os dois estilos teóricos delineados acima: as descriçôes micro e o epocalismo seriam dois estilos epistemológicos complementares, cada um contribuindo para uma compreensão de conjunto em uma escala específica (da parte ou do todo)? Ou seriam antes dois estilos radicalmente incompatíveis entre si?

A resposta mais evidente e, é o caso de se dizer, politicamente correta ao problema colocado, seria a de que são estes dois pontos de vista diferentes e complementares, cada um com sua positividade. Essa resposta fácil pode, contudo, ser problematizada em favor de uma segunda resposta mais sutil. Esta consistiria em sustentar que não são dois estilos complementares, mas antes dois estilos incompatíveis que remetem cada um a um campo específico de teorização.

A teorizaçáo microscópica e parcial seria uma forma de teorizaçáo de escopo científico, sustentada por evidências empíricas, verificável de alguma forma. Essa fundamentaçáo empírica e possibilidade de verificaçáo parece ser correlata do abandono da ambição de totalizaçáo explicativa, do abandono da tentativa de se produzir uma teoria total da história e das culturas. Por outro lado, as teorias epocalistas seriam teorias propriamente filosóficas, produzindo algo como uma filosofia da cultura em sua dimensão histórica. Essa forma de filosofia, permitindo por um lado a totalização conceitual, como indicada acima, implica tanto uma forma de inverificabilidade quanto uma carência de fundamentação em evidências empíricas.

Não tanto duas formas complementares de pensamento, mas antes dois regimes diferentes de teorização, cada um com sua especifidade epistemológica, os dois estilos básicos definidos acima oferecem ainda assim dois caminhos possíveis aos pesquisadores. A cada um, a tarefa de escolher o seu. Espera-se que esse esboço de discussão ajude de alguma forma nesse processo que, sendo em certa medida teórico, a rigor precede a elaboraçáo das teorias.

\section{Referências Bibliográficas}

BURY, Richard de. Philobiblon. Cotia, SP: Ateliê Editorial, 2004.

HAVELOCK, Eric. A Revolução da escrita na Grécia e suas conseqüências culturais. São Paulo: Editora da Universidade Estadual Paulista; Rio de Janeiro: Paz e Terra, 1996.

INNIS, Harold. The bias of communication. Toronto, Buffalo, London: University of Toronto Press, 2008.

LEVI, Giovanni. "Sobre a micro-história". In: BURKE, Peter (org.). A escrita da História: novas perspectivas. São Paulo: UNESP, 1992.

MANGUEL, Alberto. Uma História da Leitura. São Paulo: Companhia das Letras, 1997.

MCLUHAN, Marshall. Os meios de comunicação como extensões do homem. São Paulo: Cultrix, 2005. 
ONG, Walter. Oralidade e Cultura Escrita: a tecnologização da palavra. São Paulo: Papirus, 1998.

REVEL, Jacques. "Microanálise e construção do social”. In: REVEL, Jacques. (Org). Jogos de escalas: a experiência da micro-análise. Rio de Janeiro: Editora FGV, 1998.

TARDE, Gabriel. Monadologia e Sociologia. Petrópolis: Vozes, 2003.

WATSON, Alexander. J. Marginal Man: The Dark Vision of Harold Innis. Toronto, Buffalo, London: University of Toronto Press, 2006.

\section{Notas}

1. Uma versão anterior deste trabalho foi apresentada no GP Produção Editorial do XII Encontro dos Grupos de Pesquisa em Comunicação, evento componente do XXXV Congresso Brasileiro de Ciências da Comunicação, 2012. 